\title{
A REALIDADE DA DESIGUALDADE DE GÊNERO NAS CARREIRAS JURÍDICAS
}

\author{
THE REALITY OF GENDER INEQUALITY IN LEGAL CAREERS
}

\author{
Úrsula Eustórgio Oliveira de Azevedo ${ }^{1}$
}

RESUMO: Mesmo com o crescimento de participação das mulheres no mercado de trabalho brasileiro e internacional, existe uma grande diferença salarial na realização de mesmas funções em relação aos homens. Práticas no mercado de trabalho em relação a empregabilidade desqualificam injustificadamente as mulheres. O Fórum Econômico Mundial, em suas análises de mercado atualizadas, identificou que os avanços para diminuir a disparidade salarial e oportunidades no mercado de trabalho entre homens e mulheres tem sofrido um enorme retrocesso. A condição feminina geral é de vulnerabilidade e precariedade, e a desigualdade de gêneros na remuneração ainda é realidade, injusta, mesmo com legislação protetiva de direitos, como evidenciam os dados sobre a renda e empregabilidade das mulheres brasileiras. A Organização das Nações Unidas tem como meta para a Agenda 2030 a igualdade de gêneros dentre os fatores para o desenvolvimento mundial. Aplicabilidade de igualdade de gênero dentro das carreiras jurídicas.

Palavras-chave: Desigualdade de Gêneros. Igualdade Salarial. Direitos da Mulher. 1214 Desigualdade de Gênero nas Carreiras Jurídicas.

ABSTRACT: Although the participation of women in the Brazilian and international labor market has increased, there is a significant gap in the wages of men and women performing the same jobs. Labor market practices concerning employability unjustifiably disqualify women. In its updated market analysis, the World Economic Forum identified that efforts to diminish the wage disparity between men and women in the labor market had suffered an enormous setback. The general feminine condition is of vulnerability and precariousness, and the inequality in remuneration between the genders is still an unfair reality, even with protective legislation of rights as evidenced by the data on income and employability of Brazilian women. The United Nations has set the equality of genders as a goal for the 2030 Agenda and has counted it as a factor for world development. The applicability of gender equality within legal careers.

Keywords: Gender Inequality. Equal Pay. Women's Rights. Gender Inequality in Legal Careers.

\footnotetext{
${ }^{\mathrm{I}}$ Advogada - Bacharel em Direito- Universidade Estácio de Sá-UNESA-RJ; Especialista em Processo Especialista em Advocacia Trabalhista e Previdenciária pela Universidade Candido Mendes- UCAM-RJ.- Especialista em Direito Público, Especialista em Advocacia Extrajudicial e Especialista em Direito Constitucional Aplicado - Faculdade Legale Civil e- SP.
} 


\section{INTRODUÇÃO}

O presente trabalho é uma proposta de estudo sobre a desigualdade de gênero no mercado de trabalho nas carreiras jurídicas em virtude da lenta e desafiadora ascensão profissional da mulher.

A realidade sobre discriminação profissional contra a mulher no mercado de trabalho vem causando desigualdade salarial em funções similares aos dos colegas do gênero masculino. Mesmo diante da prática dessas atividades interdisciplinares e diárias, o mercado de trabalho ainda exige da mulher um comportamento mais produtivo que o homem, como se necessário fosse comprovar seu comprometimento produtivo, sua capacidade bem-sucedida de forma contínua.

A diferenciação profissional de condições acerca do trabalho exercido por mulheres acaba por assim limitando sua ascensão. A produção da mão de obra feminina não pode ser vista como um obstáculo na avaliação dos superiores para o seu desempenho no crescimento e ascensão. Promover a igualdade de gênero resulta não só em benefício dos interesses comerciais da empresa, como também tem um impacto positivo no desempenho econômico e social da sociedade de forma geral.

A importância desse trabalho está em retratar a atual realidade da mulher no mercado de trabalho objetivando o empoderamento das mulheres em relação a sua dignidade, na observância das legislações protetivas de direitos e contribuição para a eliminação de todas as formas de discriminação no acesso, remuneração, ascensão e permanência no mercado de trabalho.

A condição feminina geral é de vulnerabilidade e precariedade, e a desigualdade de gêneros na remuneração ainda é realidade injusta, mesmo com legislação protetiva de direitos, como evidenciam os dados sobre a renda e empregabilidade das mulheres brasileiras. A relevância do trabalho pode ser considerada de irrefutável indispensabilidade, pois exibe a correlação de legislação protetiva de direitos para mulher e a não aplicabilidade prática na sociedade.

As carreiras jurídicas mencionadas no estudo: advogadas, promotoras, delegadas, juízas e desembargadoras, mesmo trabalhando em imersão profunda com a normatização de direitos, ainda enfrentam as diferenças, as dificuldades em promoção profissional de modo igualitário em comparação com os colegas de gênero masculino. 
O tema é de uma severidade tão profunda que houve necessidade de estabelecimento de metas universais para o alcance da igualdade de gênero no planeta, tendo como escopo o empoderamento de todas as mulheres e meninas como passagem primordial para o desenvolvimento adequado e sustentável para todos os países de todo o mundo.

Para o desenvolvimento do presente trabalho foram utilizadas pesquisas bibliográficas fundamentadas em publicações científicas da área de direito da mulher relacionadas ao trabalho e livros sobre a desigualdade de gênero no mercado de trabalho. Alguns dados e informações foram levantados mediante pesquisas de referências bibliográficas de textos e artigos na internet, bem como em livros e periódicos de circulação nacional. A metodologia utilizada permitiu uma atualização de informações referentes ao tema, bem como uma análise a partir desses subsídios.

\section{A REALIDADE DA DESIGUALDADE DE GÊNERO NO BRASIL Garantias do princípio norteador da igualdade de gêneros}

Pode-se dizer que o ponto de partida para a igualdade de gênero em uma abordagem histórica é a Declaração dos Direitos do Homem e do Cidadão na Revolução Francesa de 1793 , onde todos seriam iguais perante a lei, proclamadas após a Revolução Francesa, quando o princípio de prevaleceria a igualdade expressa na lei, com valor absoluto. O princípio de que "todos os homens são iguais" referia-se a uma igualdade sem reservas, sem limites, o que conduzia ao entendimento de que o tratamento da lei deveria ser igual para todos, independentemente do conteúdo do tratamento. A igualdade consistia na exigência geral da lei e, portanto, estava sujeita ao princípio da legalidade. Evoluiu-se a compreensão do conteúdo da igualdade no princípio de que "todos são iguais perante a lei" e o conceito de igualdade foi relativizado, passando a ser visto como proibição de arbitragem ou discriminação.

Evolutivamente diante da Constituição Federativa Brasileira promulgada em 1988, título II, onde dispõe sobre questões essenciais como a afirmação dos direitos fundamentais, conforme artigo $5^{\mathrm{O}}$, $\S \mathrm{I}^{\mathrm{O}}$, “As normas definidoras dos direitos e garantias fundamentais têm aplicação imediata”. O artigo $5^{\circ}$, inciso I, da nossa Constituição afirma que "homens e mulheres são iguais em direitos e obrigações, nos termos desta Constituição". A Constituição do Brasil de 1988 significou um importante marco para a 
transição democrática brasileira. A Constituição Cidadã avançou no tocante ao reconhecimento dos direitos individuais e sociais das mulheres, resultado de intenso trabalho de articulação dos movimentos feministas da época. Além do tratamento diferenciado na Constituição Federal, poderá ser prevista, na legislação infraconstitucional, em ações, políticas e programas estatais, a discriminação positiva das mulheres, com o intuito de afirmar sua igualdade.

A defesa dos direitos humanos pressupõe o combate a qualquer tipo de discriminação afirmando a necessidade de ruptura das relações sociais de forma desigual construindo uma sociedade verdadeiramente livre e igualitária. Diante da urgência em promover uma reflexão responsável sobre o tema com todas as pessoas comprometidas com a construção de uma sociedade sem abusos, a igualdade de gênero torna-se essencial.

Mesmo com a Constituição Federal apresentando em seu artigo $7^{\circ}$, Inciso XX apontamento para proteção de direitos das trabalhadoras urbanas e rurais, além de outros que visem à melhoria de sua condição social há medida de proteção do mercado de trabalho da mulher, mediante incentivos específicos, nos termos da lei, tal legislação não tem seu cumprimento efetivo eficaz.

Na Consolidação das Leis do Trabalho, Decreto Lei no 5.452 de or/o5/1943², dispõe no Capítulo III, matéria da Proteção do trabalho da Mulher, Seção I especificando ainda sobre a duração, condições do trabalho e da discriminação contra a mulher, dos artigos 372 até o $40 \mathrm{I}-\mathrm{B}$.

Mesmo diante de normativa consolidada pelo artigo 373-A , DL 5452/1943 da Consolidação das Leis do Trabalho, onde expressa que ficam ressalvadas as disposições legais destinadas a corrigir as distorções que afetam o acesso da mulher ao mercado de trabalho e certas especificidades estabelecidas nos acordos trabalhistas, mulheres ainda continuam sendo discriminadas durante entrevistas para vagas no mercado privado, questionadas quanto a viabilidade de escolha pessoal para maternidade, como fator limitante ao desempenho de sua função, analisadas de forma desigual quanto aos concorrentes de gênero diferente, distinguidas quanto a apresentação do cabelo, vestimenta, impressão quanto a cor de esmalte. A comissão de Direitos Humanos da Câmara dos Deputados, em debate virtual promovido pela Secretaria da Mulher da

\footnotetext{
${ }^{2}$ Decreto Lei 5452 de ol/o5/43 - CLT - <http://www.planalto.gov.br/ccivil_03/decreto-lei/del5452.htm > Acesso em 02/10/2020
} 
Câmara junto com o ONU Mulheres, programa das Nações Unidas para as questões femininas, em análise a crise econômica do país em virtude à pandemia do causada pelo COVIDı9, foram as mulheres a mão de obra mais afetadas, conforme manifestações durante o debate, o impacto é mais significativo porque as mulheres são maioria em um setor fortemente afetado, o de serviços, além de representarem $80 \%$ dos trabalhadores informais do país, segundo a deputadas especialistas nos embates aos direitos da mulher. ${ }^{3}$

\section{I.I. Desigualdade entre homens e mulheres no mercado de trabalho global}

De acordo com os dados de 178 países coletados pela Organização das Nações Unidas - ONU no relatório sobre igualdade ${ }^{4}$, foi possível concluir que a desigualdade entre homens e mulheres persiste em um amplo espectro do mercado de trabalho global. Além do mais, ao longo das duas últimas décadas, progressos significativos realizados pelas mulheres na educação não se traduziram em melhorias comparáveis nas suas posições de trabalho. Embora 52,1\% das mulheres e 51,2 \% dos homens no mercado de trabalho sejam trabalhadores assalariados, isso por si só não constitui garantia de maior qualidade de emprego. As mulheres continuam trabalhando mais horas por dia do que os homens, tanto no trabalho remunerado quanto no não remunerado. Nos países de alta e de baixa renda, em média, as mulheres realizam pelo menos duas vezes e meia mais trabalho doméstico não remunerado e trabalho relacionado a cuidados do que os homens. Nas economias desenvolvidas, as mulheres empregadas (por conta própria ou com emprego assalariado) trabalham 8 horas e 9 minutos no trabalho remunerado e não remunerado, comparado a 7 horas e 36 minutos trabalhadas pelos homens. Nas economias em desenvolvimento, as mulheres no mercado de trabalho passam 9 horas e 20 minutos no trabalho remunerado $e$ não remunerado, ao passo que os homens gastam 8 horas e 7 minutos em tais trabalhos. A participação desequilibrada no trabalho não remunerado limita a capacidade das mulheres de aumentar as suas horas de trabalho remunerado, formal e assalariado. Como resultado, em todo o mundo, as mulheres, que representam menos de 40 por cento do emprego total,

\footnotetext{
${ }^{3}$ Agência de noticias - Câmara dos Deputados - <https://www.camara.leg.br/noticias/681393-mulheres-saomais-afetadas-por-crise-economica-provocada-pela-covid

19/\#: : :text=Mulheres\%205\% $\mathrm{C}_{3} \% \mathrm{~A}_{30}$ \%20mais\%20afetadas\%2opor\%2ocrise\%2oecon\% $\mathrm{C}_{3} \% \mathrm{~B}_{4}$ mic a\%2oprovoca da\%2opela\%20Covid\%2Di9, Mulheres\%20s\% $\mathrm{C}_{3} \% \mathrm{~A}_{30}$ \%20maioria\&text $=\% 22$ Tivemos\%20um\%20aumento\%2 oda\%20sobrecarga,mulheres\%20no\%20Brasil\%22\%2C\%2odestacou.> Acesso em 03/10/2020

${ }^{4}$ ORGANIZAÇÃO DAS NAÇÕES UNIDAS. Planeta 50-50- Relatório da ONU Disponível em: < http://www.onumulheres.org.br/planetaso5o-2030/csw/> Acesso em 9 de outubro de 2020
} 
compõem 57 por cento daqueles que trabalham menos horas ou em regime de meio período. É pulsante a desvantagem cumulativa enfrentada pelas mulheres no mercado de trabalho tendo um impacto significativo em anos posteriores. Em termos de pensões, a cobertura (tanto a legal quanto a efetiva) é menor para as mulheres do que para os homens, deixando uma lacuna de gênero na cobertura da proteção social em geral. Isso significa que cerca de 200 milhões de mulheres em idade avançada estão vivendo sem qualquer rendimento regular de uma pensão por velhice ou sobrevivência, em comparação com IIS milhões de homens.

O resultado revelado pelo Programa das Nações Unidas para o Desenvolvimento $(\mathrm{PNUD})^{5}$, e sobre o Índice de Desenvolvimento Humano (IDH), foi constatado que a desigualdade de gênero se acentuou no Brasil com os índices de divulgação no mês de março de 2017. O país ocupa o $79^{\circ}$ lugar entre 188 nações no ranking de IDH, que leva em conta indicadores de educação, renda e saúde, mas despencou 19 posições na classificação correspondente à diferença entre ricos e pobres. O Brasil se mantém estagnado como o resultado nessas avaliações, embora as mulheres tenham maior expectativa de vida e mais escolaridade, elas ainda recebem bem menos que os homens no Brasil. A renda per capita da mulher é 66,2\% inferior à de pessoas do sexo masculino. No índice de desigualdade de gênero, o país aparece na $92^{-}$- posição entre 159 países analisados, atrás de nações de maioria religiosa conservadora, a exemplo de Líbia $\left(3^{8} 8^{\mathrm{a}}\right)$, Malásia $\left(59^{\mathrm{a}}\right)$ e Líbano $\left(83^{\mathrm{a}}\right)$.

\subsection{Legislações para garantias trabalhistas da mulher na sociedade}

A Convenção no III, em seu Artigo Io de 1958 da Organização Internacional do Trabalho (OIT), ratificada pelo Brasil proíbe "qualquer distinção, exclusão ou preferência baseadas em motivos de raça, cor, sexo, religião, opinião política, ascendência nacional ou origem social, que tenham como efeito anular a igualdade de oportunidades ou de trato em emprego ou ocupação.”

A Organização Internacional do Trabalho adotou aquele que ainda é o mais completo instrumento internacional sobre a não discriminação e igualdade no mundo do

\footnotetext{
${ }^{5}$ ORGANIZAÇÃO DAS NAÇÕES UNIDAS. Desigualdade de desenvolvimento da mulher no mercado de trabalho Disponível em: $\langle$ http://www.onumulheres.org.br/wpcontent/uploads/2015/o3/Informe_Brasil_Beijing_Io.pdf $>$ Acesso em 9 de outubro de 2020 .
} 
trabalho. A Convenção sobre a Discriminação (Emprego e Profissão) ${ }^{6}$, de I958 (n⿳o. III) teve para o seu tempo uma forte visão de futuro, e mantem-se tão importante hoje como o foi no final dos anos cinquenta. Observa-se que o objetivo de eliminar qualquer discriminação no emprego ou profissão estabelecidos na Convenção ainda não foi alcançado. Para nos mantermos no caminho certo para a igualdade, é tempo de identificarmos e removermos os obstáculos que subsistem e promovermos ativamente a igualdade de gênero. Desde I9I9, a OIT tem procurado garantir os direitos no trabalho e melhorar as condições de trabalho para mulheres e homens. A igualdade está consagrada na Constituição da OIT. O princípio foi operacionalmente estabelecido pela primeira vez em I95I, quando a OIT adotou a Convenção sobre a Igualdade de Remuneração (no. Ioo). Sabendo que a discriminação na remuneração não poderia ser combatida efetivamente sem assegurar maior proteção contra a discriminação no emprego e na profissão. Houve um lentíssimo progresso com a aplicação do princípio da igualdade de oportunidades e de tratamento entre homens e mulheres e o papel preponderante da Convenção durante os últimos cinquenta anos.

Mesmo diante da recepção da Carta Magna Brasileira em 1988, nossa Constituição da República Federativa do Brasil , em 13 de abril de I995, foi editada a Lei no $9.029 / 95^{7}$, proibindo a exigência de atestados de gravidez e esterilização e outras práticas discriminatórias, para efeitos admissionais ou de permanência de relação jurídica de trabalho para as mulheres, onde era prática costumeira a solicitação desses exames para consolidar admissão empregatícia Fundamentalmente a referência a qualquer tipo de exame determinado é expressamente proibido por empresa conforme citado no art. 373-A da CLT, acrescentado pela Lei n. 9799/99 - DOU de 27.05.1999, onde é taxativo ao expressar que ressalvadas as disposições legais destinadas a corrigir as distorções que afetam o acesso da mulher ao mercado de trabalho e certas especificidades estabelecidas nos acordos trabalhistas, é vedado recusar emprego, promoção ou motivar a dispensa do trabalho em razão de sexo, idade, cor, situação familiar ou estado de gravidez, salvo quando a natureza da atividade seja notória e publicamente incompatível; é vedado ainda

\footnotetext{
${ }^{6}$ ORGANIZAÇÃO INTERNACIONAL DO TRABALHO. Convenção sobre discriminação - OIT Disponível em: < http://www.oit.org.br/node/472> Acesso em 9 de outubro de 2020.

7 Lei 9029/95 - Proibição de exigências de atestados de gravidez < http://www.planalto.gov.br/ccivil_03/leis/lgo29.htm > Acesso em 09/ı/2020
} 
exigir atestado ou exame, de qualquer natureza, para comprovação de esterilidade ou gravidez, na admissão ou permanência no emprego.

Analisando a necessidade de promulgação do dispositivo legal referido acima, constata-se que a prática e o exercício de igualdade no mercado de trabalho entre homens e mulheres é ineficaz.

A Portaria MTE no ${ }^{\text {4I, de }} 28$ de março de $2007^{8}$ em seu artigo $\mathrm{I}^{\circ}$, disciplina o registro e a anotação de Carteira de Trabalho e Previdência Social de empregados que em seu artigo I $^{\circ}$ proíbe ao empregador que, na contratação ou na manutenção do emprego do trabalhador, faça a exigência de quaisquer documentos discriminatórios ou obstativos para a contratação, especialmente certidão negativa de reclamatória trabalhista, teste, exame, perícia, laudo, atestado ou declaração relativos à esterilização ou a estado de gravidez.

O Tribunal Superior do Trabalho - TST ${ }^{9}$ garantiu através da Súmula 244, em seu Inciso IIIo, que dispõe sobre a estabilidade provisória no emprego à empregada gestante, mesmo que contratada por tempo determinado onde a empregada gestante tem direito à estabilidade provisória prevista no art.ı, inciso II, alínea b, do ADCT, mesmo na hipótese de admissão mediante contrato por tempo determinado.

A estabilidade da empregada gestante também está prevista constitucionalmente, ou seja, encontrando-se a licença situada no art. $7^{\circ}$, inciso XVIII e a estabilidade propriamente dita no art. Io, II, " $\mathrm{b}$ " do Ato das Disposições Constitucionais Transitórias.

Dispõe ainda a Constituição Federal de 1988, no Ato das Disposições Transitórias - ADCT, ser vedado ao empregador dispensar arbitrariamente a trabalhadora desde a ciência da gravidez até cinco meses após o parto, em seu artigo ıo, estabilidade provisória essa que é o período em que o empregado tem seu emprego garantido, não podendo ser dispensado por vontade do empregador, salvo por justa causa. Como a estabilidade é de emprego e não de salário, não podemos converter o referido período em indenização, salvo ordem judicial.

Ainda assim, diante de todos os princípios norteadores, houve necessidade de uma lei que tratasse especificamente da violência contra a mulher, vez que esse tipo de

\footnotetext{
${ }^{8}$ Portaria 4I TEM 28/03/2007 -TRT -Registro em CTPS 〈https://www.trt2.jus.br/geral/tribunal2/ORGAOS/MTE/Portaria/P4I_07.html>Acesso em 09/ro/2020 ${ }^{9}$ Súmula 244 TST $-<$ http://www3.tst.jus.br/jurisprudencia/Sumulas_com_indice/Sumulas_Ind_201_250.html> Acesso em $09 / 10 / 2020$
} 
violência não poderia continuar sendo tratada pela legislação geral como normas penais de natureza meramente punitivo-repressiva, em setembro de 2006, a Lei $11.340 / 06{ }^{10}-$ Lei Maria da Penha, finalmente entra em vigor, fazendo com que a violência contra a mulher deixasse de ser tratada com um crime de menor potencial ofensivo. Em 20 de agosto de 1998, a Comissão Interamericana de Direitos Humanos recebeu uma denúncia apresentada pela Senhora Maria da Penha Maia Fernandes, pelo Centro pela Justiça e pelo Direito Internacional (CEJIL) e pelo Comitê Latino-Americano de Defesa dos Direitos da Mulher (CLADEM) baseada na competência que lhe conferem os artigos 44 e 46 da Convenção Americana sobre Direitos Humanos e o artigo i2 da Convenção Interamericana para Prevenir, Punir e Erradicar a Violência contra a Mulher (Convenção de Belém do Pará ou CVM). A denúncia alegou a tolerância da República Federativa do Brasil para com a violência cometida por Marco Antônio Heredia Viveiros em seu domicílio na cidade de Fortaleza, Estado do Ceará, contra a sua então esposa Maria da Penha Maia Fernandes durante os anos de convivência matrimonial, que culminou numa tentativa de homicídio e novas agressões em maio e junho de 1983. Maria da Penha, em decorrência dessas agressões, sofre de paraplegia irreversível e outras enfermidades desde esse ano. Denunciou-se a tolerância do Estado, por não haver efetivamente tomado por mais de is anos as medidas necessárias para processar e punir o agressor, apesar das denúncias efetuadas. Denunciou-se a violação dos artigos Io (Obrigação de respeitar os direitos); 8oㅡ (Garantias judiciais); 24을 (Igualdade perante a lei) e 25을 (Proteção judicial) da Convenção Americana, em relação aos artigos II e XVIII da Declaração Americana dos Direitos e Deveres do Homem, bem como dos artigos 3, 4,a,b,c,d,e,f,g, se 7 da Convenção de Belém do Pará (CVM). A Comissão fez passar a petição pelos trâmites regulamentares. Uma vez que o Estado não apresentou comentários sobre a petição, apesar dos repetidos requerimentos da Comissão, os peticionários solicitaram que presumissem serem verdadeiros os fatos relatados na petição aplicando-se o artigo 42 do Regulamento da Comissão Interamericana de Direitos Humanos (OEA) ${ }^{\mathrm{II}}$.

\footnotetext{
ro Lei Ir.340/o6 - Lei Maria da Penha - < http://www.planalto.gov.br/ccivil_03/_ato20042006/2006/lei/lir340.htm> Acesso em 09/10/2020

II Regulamento da Comissão Interamerivcana de Direitos Humanos 〈https://www.oas.org/XXXVGA/portuguese/doc_referencia/Reglamento_CIDH.pdf〉_ Acesso em $09 / 10 / 2020$.
} 
No episódio dessa lei, originada pela experiência da Sr. ${ }^{a}$ Maria da Penha Maia Fernandes, biofarmacêutica do estado do Ceará, onde depois de sofrer várias tentativas de assassinato realizadas pelo seu marido, conseguiu denunciar internacionalmente seu caso para a Comissão Interamericana de Direitos Humanos (OEA), que, pela primeira vez, acatou uma denúncia de violência doméstica, onde judicialmente obteve o cumprimento de apenas dois anos de prisão de seu opressor. Esse processo em questão fez OEA levar o Brasil a condenação por negligência e omissão em relação à violência doméstica, sendo recomendada que fosse criada uma legislação adequada para esse tipo de violência. A lei também acaba com as penas pagas em cestas básicas ou multas, além de englobar a violência física e sexual, também a violência psicológica, a violência patrimonial e o assédio moral.

A divergência entre gêneros ainda é mais disforme quanto o tema tem uma abordagem social e racial onde o legislador fez consolidar pelo Estatuto da Igualdade Racial, Lei № 12.288 , de 20 de julho de $20 \mathrm{IO}^{\mathrm{I2}}$, em seu artigo $\mathrm{I}^{\mathrm{O}} \mathrm{PU}$, Inc. III considerando-se a assimetria existente no âmbito da sociedade que acentua a distância social entre mulheres negras e demais segmentos sociais.

\subsection{Discriminação da mulher no mercado de trabalho}

A discriminação no trabalho não é só um desperdício de talentos humanos, mas uma violação dos direitos humanos. Cada vez mais as sociedades compreendem que os locais de trabalho sem discriminação favorecem o interesse dos indivíduos, comunidades e nações. É tema do maior interesse para a ideal produtividade e crescimento dos negócios das empresas e instituições. As empresas e instituições que procuram de forma proativa pôr fim à discriminação no trabalho e assim promover a igualdade, no processo de inclusão sem discriminação para alcançar uma vasta gama de talentos. A não discriminação no emprego pode atrair os melhores candidatos ou candidatas e o processo de seleção será mais credível quando é realizável de maneira transparente e baseada no mérito profissional. A força de trabalho reflete a diversidade numa sociedade fortalecendo suas culturas e pode compreender a forma mais eficaz às necessidades progressivas na organização da sociedade. Além disso, a diversidade no trabalho pode ajudar a dissipar os

\footnotetext{
${ }^{12}$ Lei 12.288/2010 - Estatuto da Igualdade Racial - < http://www.planalto.gov.br/ccivil_03/_ato20072010/2010/lei/li2288.htm> Acesso em 09/10/2020.
} 
preconceitos e estereótipos, de forma geral, e demonstrar que uma sociedade sem discriminação é possível, efetiva e desejável.

Segundo estudos dos mais diversos tipos sobre as maiores empresas do mundo, existe uma forte correlação entre a máxima presença de mulheres nas direções dessas empresas e nos lucros sobre o patrimônio, as vendas e no capital investido. Promover a igualdade de gênero resulta não só em benefício dos interesses comerciais da empresa, como também tem um impacto positivo no desempenho econômico e social da sociedade de forma geral. Empresa é atividade econômica, organizada, com profissionalidade e intuito lucrativo tendo importante função social. A função social da empresa é alcançada quando sua atividade observa a solidariedade assim disposto no $\operatorname{artigo} 3^{\circ}$ da $\mathrm{CRFB} / 88$, promove a justiça social conforme o artigo 170, da CRFB/88, admite a busca de pleno emprego artigo I7o, inciso VIII, da CRFB/88, promove redução das desigualdades sociais disposto no Artigo 17o, inciso VII, da CRFB/88, promover o valor social do trabalho de acordo com o artigo Io, Inc IV, CRFB/88, fazer prevalecer a dignidade da pessoa humana consolidada eplo artigo Io-, inciso III, CRFB/88, observar os valores ambientais matéria do artigo 5I, inciso XIV, Lei n⿳0 8.078 de II/o9/1990 o Código de Defesa do Consumidor, dentre outros princípios constitucionais e infraconstitucionais.

Não se trata de normas meramente dispositivas, mas deve-se compreendê-las como manifestação do Estado na intervenção do domínio econômico matéria dos artigos 173 e 174 da CRFB/88, mediante a expedição de normas de comportamento compulsório, isto é cogentes. Em outras palavras, constitui em intervenção estatal na economia por direção, na classificação de Eros Roberto Grau, que consiste na edição de normas de comandos imperativos, de observância obrigatória e necessária.

Subsidiando analiticamente a desvalorização da mão de obra feminina no curso da história e ao desenvolvimento do trabalho feminino, há o caso da Draㅡ Rosalind Franklin ${ }^{\mathrm{I} 3}$ (1929-1958), Cristalógrafa, que devido a sua grandiosa pesquisa através de cristalografia de raio- $x$, conseguiu identificar a dupla hélice estrutural do DNA. Porém o Prêmio Nobel de fisiologia e Medicina de 1962 foi recebido pelos seus parceiros James Watson, Francis Crick e Maurice Wilkins onde o nome de Rosalind nem foi citado na época da apresentação da pesquisa, não recebendo nem recomendação, até porque o prêmio não

${ }_{13}$ Caso Dra Rosalind Franklin < https://revistagalileu.globo.com/Ciencia/noticia/2020/o4/quem-foirosalind-franklin-quimica-que-descobriu-estrutura-do-dna.html> Acesso em 09/ro/2020 
poder ser atribuído postumamente. Rosalind tinha falecido 4 anos antes da premiação com câncer de ovário e assim foi considerada como uma das mulheres mais injustiçadas da ciência de todos os tempos. O trabalho dessa mulher foi tão importante que sem sua cristalografia, Watson e Crick não teriam as pistas importantes para o caminho da estrutura do DNA. A "imagem 5I", uma imagem de raio-x de difração do DNA, notavelmente clara e impressionante produzida pela $\mathrm{Dr}^{-}$- Franklin e seus estudantes de graduação, sugeriu com perfeição uma estrutura helicoidal, de duas fitas para o DNA. A revelação histórica da participação da Dra - Rosalind só ocorreu devido a descoberta de cartas entre o chefe do laboratório o Dr. Wilkins e o pesquisador Dr Crick onde revelou o desconforto de ambos no trabalho com a cientista mulher onde esperavam que a fumaça da bruxaria (a mulher) pudesse sair da presença dos homens. Nessas cartas é revelado que a Dr - Rosalind já teria descoberto as imagens das hélices muito antes dos colegas. A discriminação conceituando a $\operatorname{Dr}^{\text {a }}$ Rosalind de forma negativa pelo simples fato de ser do gênero feminino, admitiu historicamente a consolidação da ineficácia do princípio norteador de igualdade de direitos entre homens e mulheres.

Socialmente, há notada inaplicabilidade de vasta legislação para promover a proteção da produção do trabalho realizado pelo gênero feminino. Há uma subcultura de inadvertida de desclassificar ou diminuir o produto do trabalho feminino. ${ }^{14}$

No Brasil, a precursora na defesa do direito das mulheres e no acesso à educação que foi a brasileira Educadora Nísia Floresta, que em 1832 lançou seu livro "Direito das mulheres e injustiça dos homens" ${ }^{15}$. Nísia Floresta considerava que existia igualdade de sexo entre homens e mulheres no que se refere à capacidade de as mulheres em atuarem, uma vez que elas não deveriam ficar restritas só à esfera privada. Defendia que as mulheres eram capazes também de adquirirem direitos tal qual os dos homens, de modo que as ações de homens e mulheres na sociedade deveriam ser julgadas com imparcialidade, e não por homens que defendem e legitimam apenas a sua atuação, como esclareceu em sua obra. Ainda escreveu o livro "Opúsculo humanitário”, também com conteúdo que defende os direitos das mulheres. Se o direito ao acesso à educação foi uma luta difícil, o acesso a outros direitos também não foi fácil. As primeiras mulheres se

\footnotetext{
${ }^{14}$ Cássia Maria Carloto- Doutora em Serviço Social pela PUC-SP. Artigo Gênero, Reestruturação Produtiva e trabalho feminino 〈http://www.uel.br/revistas/ssrevista/c_v4n2_carlotto.htm> Acesso em 09/1o/2020

is Direito das Mulheres - Nisia $\quad$ Floresta 〈https://repositorio.ufpb.br/jspui/bitstream/tede/834I/2/arquivototal.pdf > Acesso em 09/10/2020
} 
graduaram em Direito em I888, na Faculdade de Direito do Recife, entretanto não chegaram a exercer a profissão jurídica, sendo proibidas pela sociedade brasileira. De modo que coube à fluminense Dra ${ }^{\mathrm{a}}$ Myrthes Gomes de Campo, que se graduou em Direito em I898 e passou a advogar em 1924, a posição de primeira mulher advogada no Brasil.

\subsection{A realidade da desigualdade das mulheres nas carreiras jurídicas no Brasil}

Em análise as carreiras jurídicas aludidas e diferenças na realidade prática profissional desse estudo, compreendem as advogadas, promotoras e procuradoras, delegadas, juízas e desembargadoras.

A primeira mulher que efetivamente exerceu a profissão de Advogada foi a $\operatorname{Dr}^{\text {a }}$ Myrthes Gomes de Campos, fluminense, nascida em 1875, bacharelou-se na Faculdade Livre de Ciências Jurídicas e Sociais do Rio de Janeiro (UFRJ) em I898. Drª Myrthes de Campos conseguiu advogar cerca de 7 anos depois de se formar, uma vez que precisava se filiar ao Instituto dos Advogados Brasileiros, fundado em I843 (IAB). A primeira audiência tomou grande proporção e fez com que as pessoas se reunissem em frente ao edifício para acompanhar a primeira mulher a defender judicialmente uma causa, culturalmente para época foi desacreditada e surpreendeu a todos pela argumentação, obtendo sentença vitoriosa. Há 128 anos, a mulher exerce a advocacia no Brasil. Entre as profissionais advogadas as diferenças de gênero são latentes. Embora sejam praticamente metade $(49,4 \%)$ da advocacia do Rio de Janeiro, as advogadas mulheres do estado ganham $25 \%$ menos que os homens, levam mais tempo para subir na carreira, são minoria entre advogados que empregam outros colegas e ainda sofrem variados tipos de assédio. $O$ levantamento é da Caixa de Assistência de Advogados do RJ (Caarj) ${ }^{16}$, com base em dados do Instituto Brasileiro de Geografia e Estatística e do Conselho Federal da Ordem dos Advogados do Brasil. Houve um crescimento de 66,6\% do número de advogadas de 2010 até os dias atuais, contra $32,4 \%$ dos homens. As mulheres também são maioria em quase todas as faixas etárias: o número de advogados homens só supera o de mulheres na faixa etária de 60 anos para cima. O levantamento feito pela Caarj mostra que as mulheres são a maioria entre os advogados que não exercem a profissão e minoria nas instituições que

\footnotetext{
${ }^{16}$ CAARJ - Caixa de Assistência dos Advogados do Estado do Rio de Janeiro. Advocacia: Profissão mulher disponível em < https://www.conjur.com.br/dl/advogadas-rio-recebem-25-homens.part> acesso em Io/Io/2020.
} 
representam a advocacia. Atualmente, das sessenta e três (63) subseções da OAB no estado do Rio, apenas nove (9) têm mulheres na presidência, o que representa apenas $14,3 \%$ do total. Entre os principais pontos de reclamação de advogadas estão a garantia de equipamentos e prioridade para as gestantes nos fóruns, conseguir melhorias na formação, melhorias no serviço policial especializado para o enfrentamento de violência contra as mulheres, a dupla jornada profissional e doméstica, a falta de apoio do Judiciário por não entender o acúmulo de atividades das mulheres e as questões salariais e de crescimento profissional. Vale ressaltar que nunca tivemos a eleição de uma mulher na presidência da OAB Nacional.

Na Escola Superior do Ministério Público de São Paulo, no dia i8 de agosto de $2017^{17}$, entre promotoras e procuradoras de justiça houve um debate sobre os caminhos para superar a desigualdade de gênero na carreira. As mulheres são 30\% dos profissionais de carreira (um percentual já baixo frente aos $51 \%$ de presença da população feminina na sociedade paulista), mas a participação vai encolhendo nos níveis mais altos da profissão. Dos 291 cargos preenchidos atualmente de procuradores de justiça no Estado, apenas 65 (22\%) são ocupados por mulheres. No Colégio de Procuradores, são nove mulheres entre os 20 integrantes eleitos e apenas uma ocupante dos 2I cargos natos do colegiado. Refletir sobre o lugar de poder das operadoras de justiça dá a permissão quanto à ponderação sobre inúmeras questões, em especial refletir sobre o alcance e o estágio da nossa democracia. $\mathrm{O}$ lugar das mulheres nos espaços de poder e decisão é um tema central para a democracia brasileira. Lembremos ainda que a primeira mulher a alcançar o posto de Procuradora Geral no Brasil foi em 18/o9/2017, a Procuradora Drª Raquel Dodge.

Para debater sobre as dificuldades de trabalho na área policial, no dia 28 de novembro de 2019, as delegadas da Polícia Federal e Polícia Civil de São Paulo lançaram na $2^{\underline{a}}$ edição Fórum Nacional de Inteligência Aplicada para o Combate à Criminalidade (IACC), um movimento sobre mulheres na segurança pública, para estimular a participação da mulher, no segmento ${ }^{18}$. A diretora regional da ADPF-SP e presidente do Sindicato dos Delegados de Polícia Federal do Estado de São Paulo (SINDPF-SP), Dra

${ }^{17}$ Debate sobre as Mulheres no Ministério Público - MPSP 〈http://www.mpsp.mp.br/portal/page/portal/Escola_Superior/noticia?id_noticia $=17405376 \&$ id_grupo $=2257$ > Acesso em io/10/2020

I8 $\mathrm{ADPF}$ - $\mathrm{SP}$ - Debate sobre mulheres na segurança pública < https://adpf.org.br/v2/noticia/adpf/delegadas-de-policia-lancam-movimento-de-mulheres-na-segurancapublica/> Acesso em Io/10/2020 
Tania Prado, enfatizou que a ideia do movimento surgiu durante a concepção da primeira edição do IACC, em 2018, onde foi observado que os números da participação das mulheres na segurança pública ainda são baixos. Além disso, foi auferido que as que atuam em diversas esferas do segmento ainda precisam quebrar muitas barreiras, como a falta de reconhecimento dos direitos das policiais grávidas, lactantes e mães de crianças, no tocante ao acionamento para o plantão, sobreaviso e missões fora de sua base. Há sessenta e cinco (65) anos mulheres são admitidas nos quadros das polícias no Brasil. A primeira missão das policiais femininas de 1955 foi a atuação em casos envolvendo violência contra mulheres e crianças, onde foi o primeiro passo para que as mulheres pudessem ocupar postos de destaque nas forças de segurança, no País. Em 1974, Ivanete Oliveira Velloso tornou-se a primeira mulher aprovada em concurso da Polícia Civil de São Paulo e, em seguida, empossada no cargo de delegada que expôs que mesmo ainda hoje, as forças de segurança são instituições predominantemente masculinas, mas cada vez mais as mulheres estão ocupando espaço, tanto no combate à criminalidade nas ruas como nos postos de comando das polícias. Foi para reforçar essa presença feminina que, em 2019, surgiu o Movimento Mulheres na Segurança Pública com o objetivo de respeitar as especificidades de gênero, como a gestação e a maternidade. E também para incentivar mais mulheres a ingressarem na polícia e ocupar cargos de comando nas instituições. As profissionais delegadas delatam que o machismo e o preconceito na polícia perdem espaço, a cada dia, sempre que uma mulher policial mostra o seu valor e a sua capacidade de trabalho ${ }^{19}$.

O Supremo Tribunal Federal (STF) em seção a despeito do dia internacional da mulher afirmou através de sua Presidência que existe sim discriminação, mesmo em casos como de juízas que conseguem chegar a posições de igualdade, ressaltando ainda que há discriminação contra as mulheres, em todas as profissões, e este fato, o de continuar a ter discriminação contra a mulher é o que faz precisar, ainda, de determinadas ações positivas sobressaltando que a sociedade é extremamente preconceituosa em vários temas, racista em várias matérias e no caso da mulher, muito preconceituosa. Foi mencionado que se fosse igual, não haveria comentários incidentais sobre o assunto e nem um dia especial no calendário para meditação e questionamentos. Como uma ponderação sobre o desempenho do princípio norteador da igualdade de gênero no Brasil, com a inadequada aplicação segue

\footnotetext{
${ }_{19}$ ADPF- artigo sobre a mulher $-<$ https://adpf.org.br/v2/noticia/adpf/ha-65-anos-a-policia-se-rendeu-acompetencia-das-mulheres/> Acesso em ro/ $10 / 2020$
} 
abaixo a realidade desigual das mulheres no ambiente de trabalho jurídico. Associação de Juízes Federais do Brasil (AJUFE) instituiu uma Comissão para Acompanhamento do Trabalho da Mulher no Judiciário ${ }^{20}$ no dia 08 de março de 2017 convidando a Presidente do Supremo Tribunal Federal (STF), Ministra Carmen Lúcia, para relevar a necessidade, dentre outras, de o Conselho Nacional de Justiça proceder uma ampla pesquisa sobre a magistrada no Poder Judiciário brasileiro. Segundo a coordenadora dessa comissão, a juíza federal Clara da Mota Santos Pimenta, a pesquisa permitirá identificar os "entraves visíveis e invisíveis onde as mulheres têm encontrado para sua ascensão na magistratura e por que chegamos a esses números se temos um número de inscritas quase paritário com os homens". A integração da mulher juíza no mercado de trabalho resulta da atuação do dispositivo da dominação masculina que insiste em inclui-la marginalmente, ou seja, nos modos da submissão, da precarização ou da ilicitude. Há mais em comum na experiência dessas trabalhadoras do que se supõe ordinariamente: sejam as terceirizadas, as mulas do tráfico ou as juízas que enviam essas miseráveis ao inferno das masmorras brasileiras, a esmagadora maioria das trabalhadoras brasileiras ocupa as posições mais subalternas e vulneráveis. Segundo dados da PNAD Contínua (Pesquisa Nacional por Amostra de Domicílios Contínua) 2019, o número de mulheres no Brasil é superior ao de homens. A população brasileira é composta por $48,2 \%$ de homens e $51,8 \%$ de mulheres ${ }^{21}$, mesmo constatando que as mulheres estão em maioria expressiva, o Supremo Tribunal FederalSTF, em sua toda a sua história tiveram nomeados 168 ministros, onde a representação feminina obteve expressão em apenas em três juízas: a Dra Ellen Gracie Northfleet, a Dr ${ }^{a}$ Carmem Lúcia Antunes Rocha, a Drª Rosa Maria Pires Weber.

Existe desigualdade de gênero no Poder Judiciário, ambiente laboral em que as magistradas estão sub-representadas e vivenciam experiências negativas por serem mulheres. Os dados desagregados por gênero informam uma média geral de 62,7\% de homens e $37,3 \%$ de mulheres, mas há desigualdades regionais: nas 27 unidades parciais da Federação brasileira, há Estados como o Amapá, com apenas 9,8\% de representação

\footnotetext{
${ }^{20}$ AJUFE - Associação de Juízes federais do Brasil. Acompanhamento do trabalho da mulher no judiciário. Disponível em < http://www.ajufe.org/imprensa/noticias/comissao-de-acompanhamento-do-trabalho-damulher-debate-participacao-feminina-no-judiciario/> Acesso em io/1o/2020

${ }_{21} \quad$ PNAD 2019 - < https://educa.ibge.gov.br/jovens/conheca-o-brasil/populacao/18320-quantidade-dehomens-e

mulheres.html \#: :text=Segundo\%2odados\%20da\%20PNAD\%20Cont\%C $3 \%$ ADnu, $51 \% 2 \mathrm{C} 8 \% 25 \% 20$ de\%20mul heres.> Acesso em II/ $/ 10 / 2020$
} 
feminina, e outros como o Rio de Janeiro, com $48,6 \%$ de mulheres magistradas, sendo o Nordeste a Região que engloba o maior número de Estados com mais de 40\% de juízas (Bahia, Rio Grande do Norte e Sergipe). Observando os dados desagregados por ramo do Poder Judiciário ${ }^{22}$, tem-se a seguinte proporção de mulher para homens: I Mulher para I homem na Justiça do Trabalho, I Mulher para 2 homens na Justiça Estadual e I Mulher para 3 homens na Justiça Federal. É nesse ramo que se verifica a mais intensa subrepresentação feminina: $73,8 \%$ dos juízes federais são homens e 26,2\% são mulheres. Os desembargadores federais são impressionantes ıoo\% no Tribunal Regional Federal (TRF) da $5^{\underline{a}}$ Região, órgão do Poder Judiciário que somente teve uma única magistrada como desembargadora federal em toda a sua existência. Tais dados reforçam a iniquidade da situação das trabalhadoras: a mesma Região que abrange mais Estados com a melhor representatividade de gênero na $\underline{I}^{\underline{a}}$ instância é a que não tem nenhuma mulher na $2^{\underline{a}}$ instância. Seguem-no o TRFi, com 8I,5\% de homens; o TRF4, com 76\%; o TRF2, com 74\%; e o $\mathrm{TRF}_{3}$, com 72\%. Em 2016, os 2.591 juízes e desembargadores do Tribunal de Justiça de São Paulo ganharam, em média, 42 mil reais líquidos por mês. Ainda que o teto salarial da magistratura paulista fosse de 30,4 mil reais, muitos deles conseguiram ultrapassar o limite legal de vencimentos porque somaram vantagens extras - como subsídios, indenizações e gratificações, que não entram na conta. A desigualdade salarial entre gêneros também é visível nessa Corte que, até hoje, jamais foi presidida por uma mulher. Juízes homens ganham em média 44 mil reais por mês - 13,5\% a mais do que as mulheres 38 mil reais mensais ( $\left.R_{\$} 38.000,00\right)$. No caso de desembargadores, a diferença é maior: homens faturaram 55 mil reais por mês $(R \$ 55.000,00)$, $16,5 \%$ a mais do que as mulheres, que ganham em média 46 mil reais $(\mathrm{R} \$ 46.000,00)^{23}$.

Aderindo desde 20r6, à campanha da ONU Mulheres, o Tribunal e a Escola de Magistratura do Estado do Rio de Janeiro ${ }^{24}$ se comprometeram a combater a desigualdade de gênero, a discriminação e a violência contra as mulheres, e a continuar desenvolvendo ações de empoderamento do público feminino em prol da igualdade de direitos em

\footnotetext{
${ }^{22}$ BRASIL Conselho Nacional de Justiça. Percentual de mulheres na magistratura brasileira- Estudo CNJ Disponível em < http://www.cnj.jus.br/noticias/cnj/84432-percentual-de-mulheres-em-atividade-namagistratura-brasileira-e-de-37-3>acesso em il/10/2020

${ }^{23}$ SINJUS - Poder Judiciário é retrtato da desigualdade de gênero $<$ https://www.sinjus.org.br/poderjudiciario-e-retrato-da-desigualdade-de-genero/ > Acesso em II/ $10 / 2020$

${ }^{24}$ CAMPANHA COMBATE A DESIGUALDADE $-<$ https://amaerj.org.br/noticias/tribunal-de-justicae-escola-de-magistratura-do-rj-aderem-a-campanha-elesporelas-da-onu-mulheres/> Acesso em II/10/2020
} 
benefício de todas e todos. Essas ações serão realizadas por meio do estabelecimento de condições físicas e técnicas como garantias de ampliação do acesso à justiça para todas as mulheres com a aplicação integral da Lei Maria Penha, da Lei do Feminicídio e de toda legislação que contribua para punir a violência baseada em gênero, incluindo também ações de sensibilização e capacitação de membros do Judiciário. Nesse contexto, o Tribunal do Estado do Rio de Janeiro já vem desenvolvendo diferentes ações para ampliar o acesso das mulheres à Justiça através da execução da legislação em vigor. Um exemplo é o Projeto Violeta $^{25}$, coordenado pelo TJRJ e desenvolvido pelo I Juizado de Violência Doméstica e Familiar do Rio de Janeiro. A iniciativa garante a concessão de medidas protetivas em tempo recorde para mulheres vítimas de violência, providência essa que ajuda a protegê-las do risco iminente de crimes cometidos por motivação de gênero, medidas que são concedidas em quatro horas e salvam vidas.

\subsection{A desigualdade de gêneros como preocupação global}

Apesar do aumento de mulheres no mercado de trabalho nas últimas décadas, a equidade com os homens pode levar até I70 anos, segundo o Relatório Global de Equidade de Gênero de 20I6, do Fórum Econômico Mundial. De acordo com esse documento o número de mulheres em postos de responsabilidade também se mantém baixo: apenas quatro países em todo o mundo têm o mesmo número de homens e mulheres a exercerem a função de deputados, funcionários de alto nível e diretores, apesar de 95 países terem atualmente tantas mulheres como homens com formação universitária. Diante de tais dados, a desigualdade entre homens e mulheres, especialmente em sua remuneração, deve ser considerada um fato inquestionável. Suas razões já vêm sendo apontadas exaustivamente na literatura econômica de organismos internacionais, nas discussões em mídias sociais e em programas de TV.

Tal desigualdade é uma preocupação global, pois, além de injusta, reduz a produtividade e está associada a outros problemas intoleráveis, como o assédio e a violência contra a mulher. Seria importante que deixássemos de gastar energia e tempo afirmando o óbvio para que passemos a buscar meios para que essas desigualdades deixem

\footnotetext{
${ }^{25}$ TRIBUNAL DE JUSTIÇA DO ESTADO DO RIO DE JANEIRO. Projeto Violeta do Tribunal de Justiça do Estado do Rio de Janeiro Disponível em< :http://www.tjrij.jus.br/web/guest/observatoriojudicial-violencia-mulher/projeto-violeta/historico $\geq$ Acesso em II/ $/ \mathrm{o} / 2020$
} 
de existir, ou ao menos, se reduzam, em cada empresa, em cada instituição, em cada ambiente doméstico.

É preciso definir oportunidades de progresso na carreira e proporcionar flexibilidade na carga horária, adotando prazos mais longos, por exemplo, para licença maternidade e paternidade. A mulher precisa achar espaço no mercado de trabalho, assim como o homem precisa achar um espaço para participação no ambiente familiar.

De acordo com as análises da ONU Mulheres ${ }^{26}$, a saída é criar ambientes que adotam uma variedade de estilos e modelos diferenciados de trabalho. Sem isso, as organizações continuarão a perder líderes do sexo feminino. As sociedades de um modo geral estarão em contínuo crescimento se respeitarem a necessidade do papel da mulher no mercado de trabalho bem como a grande importância e contribuição no mundo em sua disponibilidade na acepção com dignidade humana.

Em apoio à Agenda 2030, a ONU Mulheres lançou a iniciativa global "Por um planeta 50-50 em 2030: um passo decisivo pela igualdade de gênero" ${ }^{27}$, com compromissos concretos assumidos por mais de 90 países. Construir um Planeta 50-50 depende que todas e todos - mulheres, homens, sociedade civil, governos, empresas, universidades e meios de comunicação - trabalhem de maneira determinada, concreta e sistemática para eliminar as desigualdades de gênero.

Na Organização das Nações Unidas na Comissão sobre as Mulheres, em todos os estudos e relatórios estão demonstrados que, quando as preocupações com a igualdade de gênero se integram nas estratégias de luta contra a pobreza, sobre o desenvolvimento econômico os resultados são muito mais eficazes, assunto do 6Iํe encontro da Comissão da ONU sobre a Situação das Mulheres (CSW), que aconteceu de 13 a 24 de março de 2017, na sede das Nações Unidas, onde deliberou sobre "O Empoderamento Econômico das Mulheres no Mundo do Trabalho em Mudança"28.

Sobre o empoderamento as mulheres e meninas devem estar preparadas para fazer parte da revolução digital no mundo. Pouquíssimas mulheres, hoje, somam I8\% dos títulos

\footnotetext{
${ }^{26}$ ORGANIZAÇÃO DAS NAÇÕES UNIDAS - ONU Mulheres . Disponível em: < http://www.onumulheres.org.br/>Acesso em I2/10/2020

27 ONU MULHERES - 50-50 < http://www.onumulheres.org.br/planeta5050-2030/paridade/> Acesso em 12/10/2020

28 ORGANIZAÇÃO DAS NAÇÕES UNIDAS- Empoderamento econômico das mulheres. Disponível em: < http://www.onumulheres.org.br/noticias/as-mulheres-e-as-mudancas-no-mundo-trabalho-por-umplaneta-50-50-artigo-da-diretora-executiva-da-onu-mulheres/>. Acesso em I2/10/2020
} 
de graduação em Ciências da Computação. De forma geral, é necessária uma mudança significativa na educação de meninas, uma atualização para alcançar uma competição com êxito aos modernos postos de trabalhos melhor remunerados. Atualmente as mulheres representam apenas um quarto da força de trabalho da indústria digital. Para o alcance igualitário nos ambientes de trabalho é necessário ampliação de participação das mulheres na vida econômica, onde possam argumentar sobre questões para gerar soluções de superação para impulsionar seu crescimento evolutivo na sociedade. A atuação com determinação para eliminação de discriminação que as mulheres se deparam em múltiplas frentes, que convergem para além do tema de gênero: orientação sexual, deficiência, idade avançada e raça.

É imperativo um ideal funcionamento das condições de trabalho para as mulheres naquelas áreas de atividade em que elas já estão excessivamente representadas e com desigual remuneração, além de contar com escassa ou nula proteção social. É preciso que todas as partes façam ajustes em favor do trabalho decente e na direção de benefícios econômicos para todas as pessoas, sem qualquer tipo de discriminação, como prevê a Agenda 2030 para o Desenvolvimento Sustentável com a promessa de um mundo igualitário.

\section{CONCLUSÃO}

Ainda que a Constituição Federal de 1988, a Carta Magna, garanta a igualdade de direitos e garantias entre os homens e mulheres e mais diversas legislações protetivas à igualdade de direitos trabalhistas, permanece ainda uma grande distância entre a realidade normativa e sua real aplicabilidade no mercado de trabalho em carreiras jurídicas.

Simone de Beauvoir, precursora da denominada "Segunda Onda" ${ }^{29}$ do feminismo, teorizando o papel da mulher na sociedade, discutiu sobre o caráter indefinido para o conceito de gênero, chamando a atenção para as inúmeras construções sociais acerca de ser homem, e, especialmente, de ser mulher. Beauvoir questiona “o que é uma mulher?" e refuta a noção de que "ser mulher" se resumiria na circunstância de possuir um útero, chegando à conclusão de que "todo ser humano do sexo feminino não é, portanto, necessariamente mulher; cumpre-lhe participar dessa realidade misteriosa e ameaçada que

29 BEAUVOIR, S. D. O segundo Sexo. 2. ed. São Paulo: Difusão Europeia do Livro, v. 2, 1967 
é a feminilidade" Gênero, nessa perspectiva, envolveria aspectos socioculturais e históricos que afetariam diretamente o indivíduo, não sendo decorrência natural de suas características corporais.

O ambiente de trabalho jurídico tem apresentado injustas avaliações criteriosas na ascensão para as carreiras profissionais desempenhadas pelas mulheres. Enquanto profissionais mulheres, sempre por comportamento tendencial, vêm demonstrado melhor capacidade laborativa e busca de qualificação profissional, em valorização de suas funções, ainda apresentam salários diferenciados a menor dos colegas de outro gênero. $O$ mercado de trabalho jurídico, apresenta resistência para nomeação de profissionais mulheres no desempenho de lideranças de suas carreiras jurídicas. Esse tema é de extrema de relevância de paradoxo jurídico e social, pois há diversos estudos comprovando a eficácia na gestão de carreiras profissionais com liderança feminina.

Rodolfo Pamplona Filho, Mestre e Doutor em Direito e Juiz Titular da $32^{\underline{a}}$ Vara do Trabalho de Salvador/BA, reporta em seu artigo "Discriminação de Gênero e Orientação Sexual nas relações de Trabalho", que mesmo que as desigualdades entre homens e mulheres construídas na esfera cultural e social, há uma forte ideologia cuja intenção é fazer crer que a divisão dos papéis entre eles seria naturalmente determinada pela condição biológica. O valor do trabalho, entendido como necessidade, sobrevivência, independência, realização individual deveria sim ter um papel central na estruturação da identidade do ser humano. Nessa senda, ser rejeitado, criticado ou humilhado desperta um sentimento de insegurança, além de ferir a dignidade do indivíduo, ainda mais pela diferenciação de gênero.

As normas dependem da conscientização social e da necessidade pactual de mudanças no comportamento. Miguel Reale, ao referir-se sobre os tipos primordiais de normas, diz que o essencial é "reconhecer que as normas jurídicas, sejam elas enunciativas de formas de ação ou comportamento, ou de formas de organização e garantia das ações ou comportamentos, não são modelos estáticos e isolados, mas sim modelos dinâmicos que se implicam e se correlacionam, dispondo-se num sistema, no qual umas são subordinantes e outras subordinadas, umas primárias e outras secundárias, umas principais e outras subsidiárias ou complementares, segundo ângulos e perspectivas que se refletem nas 
diferenças de qualificação verbal" ${ }^{30}$. A norma jurídica pode, também, ser concebida como a manifestação de um ato de vontade do poder, através do qual a conduta humana individualizada possa ser obrigatória, permitida ou proibida. Por isso, situa-se no comportamento ético, pois seu objetivo será sempre o de regular a conduta dos homens em sociedade, apresentando-se como uma ordem de dever das ações humanas. Diante de todas as prerrogativas protetivas de direitos das mulheres, a legislação deve ser respeitada, cumprida, ter ampliada sua eficácia, em concordância com a finalidade esperada, devendo ser esforçada pela sociedade em consenso pelo princípio da isonomia.

Perante a circunstância do mercado global atual, no formato em que segue, serão necessários maisizo anos para que a haja igualdade salarial entre homens e mulheres conforme todas as análises e estudos dos institutos especializados em direitos da mulher. Ações eficazes formatadas a partir do respeito incondicional a igualdade de direitos e da legislação existente precisam ser consideradas efetivamente, combatendo a desigualdade de gêneros no ambiente de trabalho e todo o preconceito vigente de gênero.

Visando atuação na diminuição de desigualdade nas carreiras jurídicas a Associação Brasileira de Mulheres de Carreira Jurídica (ABMCJ) vem agindo tendo representação em vinte e cinco estados brasileiros. Suas atividades atuam com formação de Comissões Estaduais para lidar com a atuação da mulher como cidadã e profissional. A associação conta, ainda, com suporte de organizações internacionais, como a Organização das Naçõe Unidas (ONU) , Fundo das Nações Unidas para a Infância (UNICEF) e a Organização Internacional de Trabalho (OIT).

Com o propósito combater a discriminação contra as mulheres no sistema de justiça. Foi fundada a entidade civil Themis. formada por advogadas e cientistas sociais feministas, que favorecem a sociedade como um todo, por meio de programas e rede de apoio. Muitas das conquistas das mulheres brasileiras, como a ampliação do acesso à justiça, programas de fortalecimento do conhecimento dos direitos das mulheres e das discussões que fomentaram na criação da Lei Maria da Penha, bem como sua implantação, foram sustentadas e apoiadas pela organização Themis.

Tendo em vista as necessidades de um mundo mais coerente e justo, em virtude de desenvolvimento de toda a sociedade, o princípio norteador da igualdade de gêneros nas

${ }^{30}$ REALE, Miguel. Lições preliminares de direito. $2^{\text {a }}$ ed. São Paulo. Bushatsky, 1974. 
carreiras jurídicas deve prevalecer, sendo robustecido seriamente onde sua inaplicação deve ser combatida preponderando sempre a dignidade humana, princípio norteador do caminho do bom direito.

\section{REFERÊNCIAS}

AJUFE - ASSOCIAÇÃO DE JUÍZES FEDERAIS . Acompanhamento do trabalho da mulher no judiciário. Disponível em: http://www.ajufe.org/imprensa/noticias/comissaode-acompanhamento-do-trabalho-da-mulher-debate-participacao-feminina-no-judiciario/> Acessoem:II/10/2020.

BRASIL. Conselho Nacional de Justiça. Censo do Poder Judiciário. Vetores iniciais e dados estatísticos. Brasília: CNJ, 2014. 2I2p. Disponível em: http://www.cnj.jus.br/images/dpj/CensoJudiciario.final.pdf Acesso em: II de outubro de 2020. As "opiniões das magistradas sobre desigualdade de gênero" foi objeto do item 3.5 do Censo (p. 85 e seguintes).

BRASIL. Conselho Nacional de Justiça. Percentual de mulheres na magistratura brasileira- Estudo CNJ Disponível em: < http://www.cnj.jus.br/noticias/cnj/84432percentual-de-mulheres-em-atividade-na-magistratura-brasileira-e-de-37-3> Acesso em: II/ $10 / 2020$

\section{CAARJ - CAIXA DE ASSISTÊNCIA AOS ADVOGADOS DO ESTADO DO RIO} DE JANEIRO. Advocacia: Profissão mulher disponível em: < https://www.conjur.com.br/dl/advogadas-rio-recebem-25-homens.part> acesso em: $09 / 10 / 2020$

GUZMÁN, Virginia. A eqüidade de gênero como tema de debate e de políticas públicas. In: FARIA, Nalu; SILVEIRA, Maria Lúcia e NOBRE, Míriam (orgs.). Gênero nas políticas públicas. SOF, Cadernos Sempreviva, São Paulo, 200o..

MARTINS, Sergio Pinto. Práticas discriminatórias contra a mulher e outros estudos. São Paulo : LTr, 1996. 
MINISTÉRIO PÚBLICO DO ESTADO DE SÃO PAULO.. Debate para superação da desigualdade de gêneros no Ministério Público. Disponível em: 〈http://www.mpsp.mp.br/portal/page/portal/noticias/evento?id_evento=17314544\&id_gr upo=II8>Acesso emi2/10/2020.

PAMPLONA FILHO, Rodolfo e VIEGAS, Claudia Mara de Almeida - Revista Argumentum - RA - Discriminação de Gênero e Orientação Sexual nas relações de Trabalho- , eISSN 2359-6889, Marília/SP, V. 21, N. I, pp. 39-64, Jan.-Abr. 2020

ORGANIZAÇÃO DAS NAÇÕES UNIDAS- Empoderamento econômico das mulheres. Disponível em:<http://www.onumulheres.org.br/noticias/as-mulheres-e-as-mudancasno-mundo-trabalho-por-um-planeta-50-50-artigo-da-diretora-executiva-da-onumulheres/>. Acesso em:12/10/2020.

TRIBUNAL DE JUSTIÇA DO ESTADO DO RIO DE JANEIRO. .Projeto Violeta do Tribunal de Justiça do Estado do Rio de Janeiro. Disponível em: http://www.tjrj.jus.br/web/guest/observatorio-judicial-violencia-mulher/projetovioleta/historico Acesso em: II/ro/2020. 